\title{
Latency of self-administered shock as a function of its intensity and probability'
}

\author{
ROBERT D. HARE, DENNIS L, KREBS, TERENCE D. CREIGHTON AND WILLIAM M. PETRUSIC
}

UNIVERSITY OF BRITISH COLUMBIA

Ss were given 40 trials on which they were required to administer a shock to themselves within $15 \mathrm{sec}$. of hearing a buzzer. The intensity (mild or strong) and probability $(100 \%$ or $50 \%$ ) of shock varied at random from trial to trial. The latency of self-administered shock was generally very short $(<1.0 \mathrm{sec}$.$) and was unrelated to the parameters of shock$ used. The data were discussed in terms of the occurrence of preparatory responses.

An earlier study (Hare, 1966) found that the preference for delay of inevitable shock was unrelated to the probability of shock occurrence and only marginally related to shock intensity. Thus, when given 30 trials in which they were required to choose between receiving a shock after a delay of 0, 2, 5, 10 and 15 sec., and in which the intensity of shock increased from a very low level on the first trial to one that was very unpleasant on the 30th, 11 Ss chose immediate shock on almost every trial. The choices of the remaining nine Ss were distributed over all or most of the delays, although as the shock level increased there was a tendency to shift towards the 0 and $2 \mathrm{sec}$. delays. The difference in choice behavior of Ss shocked on every trial and those shocked on only $50 \%$ of the trials was not significant.

In an attempt to obtain a more sensitive measure of the preference for delay of shock under different intensities and probabilities, Ss in the present experiment were required to administer shock to themselves at any point within a 15 sec.-interval after receiving the appropriate signal. The parameters of shock (intensity and probability) in this within-Ss design varied from trial to trial with the assumption being that the latency of the S's response would be related to these parameters.

Method

The Ss were 15 male and 15 female volunteers. Fourteen of the Ss had also participated in the earlier study, and provided a basis for comparing the two procedures.

The $\mathrm{S}$ sat before a sloping panel upon which was mounted a spring-loaded lever. Above the lever were four cards which described the conditions under which shock was to be administered, viz., "weak shock$50 \%$ chance," "weak shock-100\% chance," "strong shock-50\% chance," and "strong shock-100\% chance." A small red light above each card indicated which shock conditions were operative on each trial.

Prior to beginning the experiment, the intensity of shock to be used was determined by administering a series of $500 \mathrm{msec}$. sample shocks through concentric electrodes attached to the mid-dorsal surface of the left forearm (Tursky, Watson, \& O'Connell, 1965). The "weak shock" was a level rated by the $\mathrm{S}$ as mildly unpleasant, while the "strong shock" was one rated as painful. Once these levels had been determined, the $S$ 's attention was directed to the lever and the descriptive cards and their function explained. He was told that when the light above a card went on, the shock that he would receive when he pressed the lever would have the characteristics described in the card. Five sec. later, a buzzer sounded indicating to the $S$ that he was to press the lever and thus to administer shock to himself. He could do so at any time that he wished, as long as it was within 15 sec. after the buzzer. If he had not pressed the lever by the end of the $15 \mathrm{sec}$. period, shock was administered automatically.

A total of 40 trials, each 30 sec. apart, was given, with each of the four shock conditions being presented 10 times in random order. Prior to each trial, the S was required to place his hand in a predetermined position in front of the response lever.

\section{Results and Discussion}

The median response-latencies, measured from the onset of the buzzer to the depression of the shockadministering lever, are presented in Table 1. The number of Ss in each shock condition whose latencies fell within various intervals is also presented. The data for male and female Ss have been combined since preliminary analysis indicated that none of the differences between them was significant.

It is evident from Table 1 that most Ss administered shock to themselves very quickly. As a matter of fact, it appears that the latencies of some of the Ss represented their reaction times to the buzzer. A few Ss, on

Table 1. Median response-latency and number of Ss whose latencies fell within each interval as a function of shock intensity and probability.

\begin{tabular}{lcccc} 
Lotency & \multicolumn{5}{c}{ Shock Condition } \\
(sec.) & \multicolumn{3}{c}{ Mild Shock } & \multicolumn{2}{c}{ Strong Shock } \\
$0.400-2.999$ & $50 \%$ & $100 \%$ & $50 \%$ & $100 \%$ \\
\hline $1.000-1.499$ & 22 & 19 & 18 & 17 \\
$1.500-1.999$ & 4 & 8 & 4 & 6 \\
$2.000-2.499$ & 0 & 0 & 3 & 2 \\
$2.500-2.999$ & 0 & 2 & 1 & 1 \\
$3.000-3.499$ & 2 & 0 & 0 & 1 \\
$3.500-3.999$ & 0 & 0 & 0 & 0 \\
over 4.000 & 0 & 0 & 3 & 1 \\
Median & 2 & 1 & 3 & 1 \\
\hline
\end{tabular}


the other hand, had much longer latencies. This is analogous to the earlier findings that while most Ss preferred immediate shock, a few preferred shock that was delayed (Cook \& Barnes, 1964; Hare, 1966). In addition, however, eight $\mathrm{Ss}$ in the present study had mean latencies of between 1 and $2 \mathrm{sec}$. It is quite possible that these Ss "selected" this slight delay because it gave them time to "get set" for the shock. A similar observation was made in the previous study (Hare, 1966) in which some Ss shifted to a 2 sec. delay as shock became very strong. One way of looking at the latencies in the present study, as well as the choices of delay of shock in the previous one, would be to assume that they both represent, at least in part, individual differences in length of time required by Ss to make the necessary preparatory responses prior to the reception of shock. ${ }^{2}$ As a matter of fact, it is possible that in the few studies published, most Ss have chosen immediate shock simply because this alternative was closest to their most preferred delay (which for most people may be somewhere around 1 sec. in the tasks used). Parenthetically, even rats apparently would rather receive a shock for which they can make preparatory responses (e.g., a signal-shock sequence) than a shock for which such responses are not possible (e.g., a shock-signal sequence; cf., Perkins et al, in press). Indeed, it appears that the opportunity of making preparatory responses may reduce the subjective intensity of shock in both rats (Lykken, 1962) and humans (Lykken, 1959).

In order to determine whether response-latency was related to the shock conditions used, the mean latencies of each $\mathrm{S}$ under each of the four shock conditions were ranked and subjected to a Friedman two-way analysis of variance (Siegel, 1956). The results clearly indicate that when all Ss are considered together, responselatencies were unrelated to the shock conditions under which the response was made $\left(x^{2}=1.7, d f=3, p>.50\right)$. However, it is noteworthy that of the four Ss whose latencies under mild shock conditions were relatively long (>1.5 sec.), three showed a marked reduction in latency when strong shock was involved. This supports an earlier impression (Hare, 1966) that the effect of shock intensity upon the preferred delay of shock may be obscured by the fact that most Ss prefer immediate shock no matter what the intensity. This may mean that any attempt to demonstrate intensity (and perhaps probability) effects upon the preference of delay of shock will require the use of Ss who ordinarily do not exhibit strong preferences for immediate shock.

There is also a procedural detail that may have tended to obscure any relationship between the parameters of shock and response-latency and which may also have attenuated the individual differences in re- sponse-latency. This is the 5 sec. interval between the onset of the light (which told of the shock condition operative on a given trial) and the presentation of the buzzer (which indicated to $S$ the beginning of the interval during which a shock-administering response could be made). A 5 sec. interval was used in an attempt to prevent the response-latencies from being influenced by any differences that may have existed in the time required for the perception and comprehension of the contents of the "shock-condition" cards. However, it is possible that this interval could have been used by many Ss to make the necessary preparatory responses with the result that their responselatency to the buzzer would be very short. Perhaps a better procedure would be to train Ss on the use of the cards before the experiment and then to dispense with the 5 sec. interval. Alternatively, a between-Ss design could be used.

Since 14 of the Ss in this study had also participated in the earlier one, it was possible to compare their behavior under both procedures. Nine of these Ss chose immediate shock almost exclusively in the earlier study. Their median response-latency in the present one was $0.898 \mathrm{sec}$. (range from 0.491 to 2.512). The median latency of the remaining six Ss, whose choices had involved many delayed and few immediate shocks, was $1.500 \mathrm{sec}$. (range from 0.774 to 5.724 ). A MannWhitney $U$ test indicated that the difference was significant $(U=12, p<.05$, one-tailed test), suggesting that the Ss involved were reasonably consistent in the delay of shock preferred.

\section{References}

Cook, J. O., \& Bames, L. W. Choice of delay of inevitable shock. J. abnorm. soc. Psychol., 1964, 68, 669-672.

Hare, R. D. Preference for delay of shock as a function of its intensity and probability. Psychon. Sci., 1966, 5, 393-394.

Lykken, D. T. Preliminary observations on the preception phenomenon. Psychophysiol. Measmt. Newsltr., 1959, 5, 2-4.

Lykken, D. T. Preception in the rat: autonomic response to shock as function of length of warning signal. Science, 1962, 137, 665-666.

Perkins, C. C., Seymann, R. G., Levis, D. J., \& Spencer, H. R. Factors affecting preference for signal-shock over shock signal. $J$. exp. Psychol., in press.

Siegel, S. Nonparametric statistics for the behavioral sciences. New York: McGraw-Hill, 1956.

Tursky, B., Watson, P. D., \& O'Connell, D. N. A concentric shock electrode for pain stimulation. Psychophysiology, 1965, 1, 296298.

\section{Notes}

1. Supported by Grant APA-139 from the National Research Council of Canada and by the University of British Columbia Committee on Research. The helpful comments of Bert Tindall are appreciated. 2. Note however, that in the earlier study these preparatory responses could occur either before, during or after the lever had been depressed whereas in the present study they could only occur before or during depression of the shock-lever. 